\title{
Endoscopic Sphenopalatine Artery Ligation in Posterior Epistaxis
}

\section{Sigdel B}

Department of Otolaryngology \& Head and Neck Surgery, Gandaki Medical College, Pokhara, Nepal

Received: July 15, 2020

Accepted: October 10, 2020

Published: December 30, 2020

Cite this paper:

Sigdel B. Endoscopic Sphenopalatine Artery Ligation in Posterior Epistaxis. Nepal Journal of Medical Sciences 2020;5(2):10-15. http://dx.doi.org/10.3126/njms.v5i1.36705

\begin{abstract}
Introduction: Posterior epistaxis brings us with a more challenging condition that can even threaten the life of a patient. Approaching the posterior nasal cavity is not an easy task because of its anatomical complexity and impending vision by turbinate. Increase endoscopic anatomic details of lateral nasal wall and endoscopic expertise with high definition camera leads to a higher success rate of endoscopic sphenopalatine artery ligation.
\end{abstract}

Methods: This prospective study was conducted in patients with refractory posterior epistaxis between January 2017 to December 2019. All patient who had undergone Endoscopic Sphenopalatine artery ligation were included in this study. The site of bleeding was confirmed with the help of a rigid endoscope. Bipolar cauterization or clipping was performed to stop bleeding. Data analysis was done by using SPSS 26.0 version.

Results: Twenty nine patients who had undergone Endoscopic sphenopalatine artery for posterior epistaxis were included during this study period. The mean age of the patient was $53.31 \pm 18.65 y$ years. The site of bleeding was mostly from the left in $20(75.9 \%)$ cases and 10 $(34.4 \%)$ cases had severe bleeding that needed a blood transfusion. No recurrence of bleeding was found during follow up period. The severity of bleeding was significantly correlated with the age of patients $(\mathrm{p}<0.003)$. Out of 29 patient, 27 patients had undergone bipolar diathermy and 2 patients clipping was done.

Conclusion: Sphenopalatine artery ligation is an effective management strategy for surgical control of refractory epistaxis. The early timing of sphenopalatine artery ligation may lead to reductions in length of stay.

Keywords: Endoscopy; Posterior Epistaxis; Sphenopalatine Artery Ligation

\section{INTRODUCTION}

Posterior epistaxis is a challenging type of epistaxis that can even threaten the life of a patient. ${ }^{1,2}$ This condition is controlled by posterior nasal packing done either by

Correspondence to: Dr. Brihaspati Sigdel

Department of Otolaryngology conventional ribbon gauge pack or intranasal balloons. ${ }^{3,4}$ In an elderly patient who are Gandaki Medical College Teaching Hospital

Pokhara, Nepal

Email: brihassig1@gmail.com respiratory compromise, it may result in

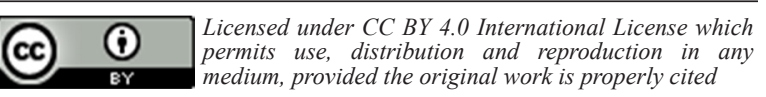


hypoxia, cardiac arrhythmias or even death. ${ }^{5}$ It has a significant chance of rebleeding after the removal of the pack.

In early 1980, transantral maxillary artery ligation was performed. ${ }^{6,7}$ But it requires more destructive procedure like caldwall-luc operation. ${ }^{8}$ Sometimes such cases demands the opening of the neck and ligate external carotid artery. ${ }^{9}$ Another alternative to surgery is embolization of the maxillary artery. ${ }^{10}$ But this procedure requires a well-equipped intervention radiology department. Increase endoscopic anatomic details of the lateral nasal wall leads to a higher success rate of endoscopic sphenopalatine artery ligation. ${ }^{11,12}$ This study aims to observe the role of endoscopic sphenopalatine artery ligation in posterior epistaxis.

\section{METHODS}

This prospective study was conducted in patients with refractory posterior epistaxis between January 2017 to December 2019. All patient who had undergone Endoscopic Sphenopalatine artery ligation were included in this study. The study protocol was approved by the institutional ethical committee. Written and informed consent was taken from each patient.

\section{Management Protocol of patients:}

All the patient with posterior epistaxis were packed with either ribbon gauge or sponge (merocele). In the meantime, complete history of the patient and blood test such as CBC, BT, CT, PT, INR, platelet count. CT scan of the patient was also performed. All the patient were admitted to the hospital. Rigid Endoscopy was performed on all the patient who have posterior epistaxis and confirms the site of bleeding. The patient who had posterior nasal bleeding on endoscopic examination were posted for endoscopic sphenopalatine artery ligation. Patient with recurrent epistaxis from the same site was immediately planned. Patient undergoing anticoagulants therapy were operated when the INR was below 2 . Patient with hypertension was first consulted with the cardiologist and optimized blood pressure below $140 / 90 \mathrm{mmHg}$ then only surgery was performed.

\section{Surgical technique:}

Patients were kept in flexed position after General or Local anaesthesia. The nasal pack which was kept previously was removed and endoscopic examination was performed and posterior part of the nose was packed with ribbon gauge neuropathies soaked with a mixture of $2 \mathrm{ml}$ in 2\%xylocaine with 1:80000 adrenaline, $2 \mathrm{ml}$ of $0.05 \%$ oxymetazoline. Once the nose is decongested, the posterior fontanelle of the maxillary sinus was located by palpating under the bulla ethmoidal is with a right-angled curve sucker. The junction between the posterior fontanelle and lateral nasal wall was identified. An incision was given from the undersurface of the horizontal portion of ground lamella to the insertion of the inferior turbinate on the lateral nasal wall. A suction freer's elevator was used to raise the flap in the subperiosteal plane. Anterior face of ethmoid was identified. And the mucosa was elevated for few millimetres. The flap comes away from the lateral nasal wall. There is often a bony lip just anterior to the foramen, which helps to identify the artery. Confirmation of the foramen is achieved by gentle insertion of a double right-angled ball probe into the foramen. Gentle dissection to be done until the artery is identified. After that bipolar cautery was used. The flap was replaced and the incision was covered with a small piece of gel foam. A small pack was kept for $24 \mathrm{hr}$. The patient was discharged on the saline drop for the next 48 hour.

Data were entered in an MS Excel sheet. Analysis was done by using SPSS 26.0 version. Frequency and percentage calculated by frequency statistics. Analysis of variance was used to show the relationship between severity of bleeding with age and sex. Significance shows $\mathrm{p}<0.05$.

\section{RESULTS}

Twenty nine patients who had undergone Endoscopic sphenopalatine artery for posterior epistaxis were included during this study period. Female: Male ratio is $1.07: 1$. The mean age of the patient was $53.31 \pm 18.65$ years. 
The age range was between 18 to 77 years. The Median follow-up period was 18 month. The site of the bleeding right side was 22 (75\%) idiopathic bleeding 20(70.4\%) (Table 1)

\section{Table 1: Profile of patients}

\begin{tabular}{lll}
\multirow{2}{*}{ Gender } & Parameter & Frequency (\%) \\
& Male & $14(48.3 \%)$ \\
Age & Female & $15(51.7 \%)$ \\
& $<20$ & $1(3.4 \%)$ \\
Site of bleeding & $20-40$ & $6(20.7 \%)$ \\
& $40-60$ & $9(31.0 \%)$ \\
Type of anaesthesia & $60-80$ & $13(44.8 \%)$ \\
\multirow{3}{*}{ Risk factor } & Left & $22(75.9 \%)$ \\
& Right & $7(24.1 \%)$ \\
Blood transfusion & GA & $25(86.2 \%)$ \\
& LA & $4(13.8 \%)$ \\
& idiopathic & $20(74.1 \%)$ \\
& Hypertension & $6(22.2 \%)$ \\
& Nasal polyposis & $3(11.1 \%)$ \\
\hline
\end{tabular}

The overall regression model of analysis of variance shows the severity of bleeding was significant with age and $\operatorname{sex}\left(\mathrm{F}(2,26), \mathrm{p}<0.001 \mathrm{R}^{2}=0.85\right)$. coefficient test of each variable with only show age was only significant with age. $(\mathrm{p}<0.003)$ (Table 2$)$

Table 2: Oneway Analysis of variance of severity of bleeding with age and sex of patients

\begin{tabular}{|c|c|c|c|c|c|}
\hline Model & Sum of Squares & df & Mean Square & $\mathrm{F}$ & Sig. \\
\hline Regression & 15.472 & 2 & 7.736 & 84.171 & $.000^{\mathrm{b}}$ \\
\hline Residual & 2.390 & 26 & .092 & & \\
\hline Total & 17.862 & 28 & & & \\
\hline
\end{tabular}

\begin{tabular}{cccccccc} 
Coefficients & $\begin{array}{c}\text { Unstandardized } \\
\text { Coefficients }\end{array}$ & $\begin{array}{c}\text { Stand. } \\
\text { Coeff. }\end{array}$ & t & Sig. & \multicolumn{2}{c}{ Correlations } \\
& B $\quad$ Std. Error Beta & & & $\begin{array}{c}\text { Par- } \\
\text { order }\end{array}$ & tial Part
\end{tabular}

\begin{tabular}{cccccccccc}
$\begin{array}{c}\text { Severity of } \\
\text { bleeding }\end{array}$ & -.326 & .235 & & -1.386 & .178 & & & \\
sex & .207 & .113 & .132 & 1.836 & .078 & .179 & .339 & .132 \\
age & .039 & .003 & .915 & 12.733 & .000 & .921 & .928 & .913 \\
\hline
\end{tabular}

a.Dependent Variable: severity of bleeding

b.Predictors: (Constant), age, sex group

GA: General Anaesthesia, LA: Local Anaesthesia

No recurrence of bleeding during follow-up period. Out of 29 patient, 27 patients were 
undergone bipolar diathermy and 2 patients were performed clipping. (Figures 1, 2 \& 3)

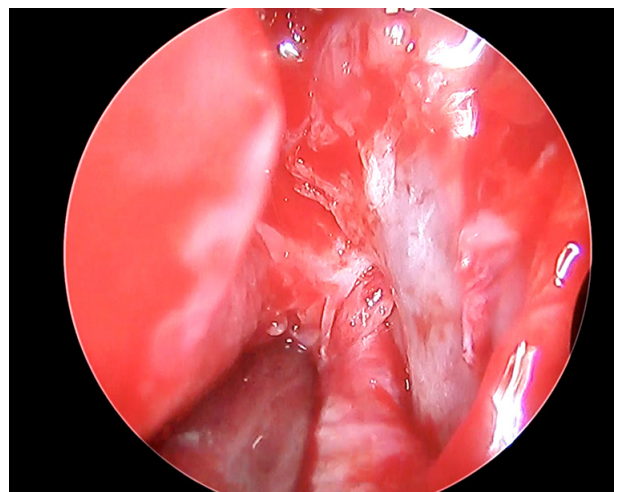

Figure 1: Showing endoscopic view of Sphenopalatine Artery

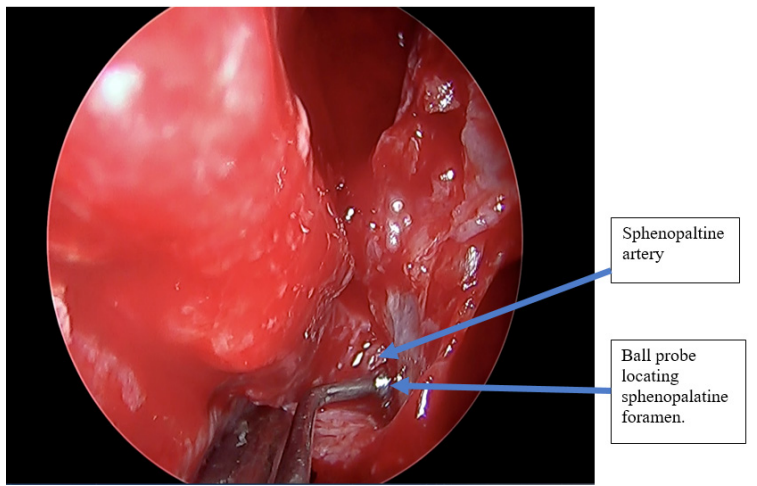

Figure 2: Ball probe just before entering in sphenopalatine foramen

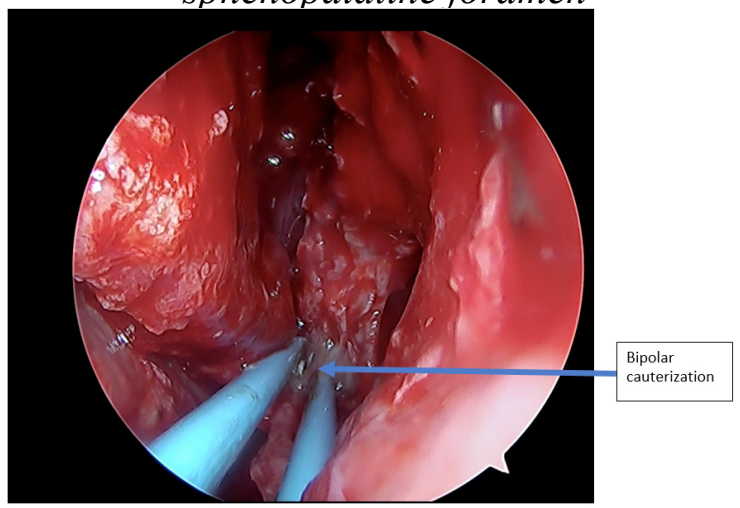

Figure 3: Bipolar cauterization of sphenopalatine artery

\section{DISCUSSION}

Intractable posterior epistaxis is a frustrating condition for both patients and surgeons. Optimal treatment is controversial. Our current treatment is based on the surgical ligation of the Sphenopalatine artery in refractory posterior epistaxis. The ligation reduces the discomfort, cost and potential medical morbidity compared to nasal packing. ${ }^{11,12,13,14,15,16}$

This procedure was first described by Prades J. ${ }^{17}$ Endoscopic SPA ligation was first described by Budrovich and saetti in 1992. ${ }^{18}$ Proper knowledge of regional anatomy, nasal vasculature, appreciation of sphenopalatine artery has utmost value. SPA ligation has low morbidity due to no facial incision and infraorbital paresthesia. ${ }^{14,19,20,21}$ Recurrent bleeding after this procedure was present in $13 \%$ of cases as noted by Syndermen $\mathrm{CH}$ et al. ${ }^{8}$ It has a success rate higher than $95 \% .{ }^{22}$ Unfortunately, we did not get any such cases of bleeding in our study.

The overall regression model of analysis of variance was applied to the severity of bleeding for age and sex. It shows that the severity of bleeding was significantly increased with age and sex $\left(\mathrm{F}(2,26), \mathrm{p}<0.001 \mathrm{R}^{2}=0.85\right)$. The coefficient test of each variable showed that age was significantly associated with the severity of epistaxis. $(\mathrm{p}<0.003)$

Although embolization has equal efficacy to SPA ligation for cessation of posterior epistaxis, due to lack of proper setup in our hospital, this procedure is not carried out. Embolization is mainly performed for high risk and those who are unfit for general anaesthesia. ${ }^{10,23}$ Despite having equal efficacy, it has its drawback includes brain hemiplegia, facial pain, and facial paresthesia, ophthalmoplegia and blindness. $^{7}$ Ligation was done in $4(13.8 \%)$ cases under local anaesthesia. Similar finding found a study by Jonas et al. ${ }^{24}$ we believe Spa ligation can be done who have unfit for general anaesthesia in selected cases, that bypass anaesthesia unfit barrier.

It should be needed to determine the costeffectiveness of this treatment algorithm compared to posterior nasal packing, embolization and other surgical procedure too.

In our experience, SPA ligation is the first option for definitive management of posterior epistaxis because this showed a high success rate with low morbidity. The limitation of this 
study is expertise in endoscopic endonasal anatomy procedure knowledge and high-end endoscopy operative room setup is important.

\section{CONCLUSION}

Endoscopic SPA ligation is a safe and effective means of controlling intractable posterior epistaxis. It requires a better understanding of the endoscopic anatomy of the nose and sphenopalatine artery to ensure technical success.

\section{CONFLICT OF INTEREST}

None

\section{SOURCES OF FUNDING}

None

\section{REFERENCES}

1. Tan LK and Calhoun KH. Epistaxis. Med Clin North Am. 1999;83(1):4356. https://doi.org/10.1016/S00257125(05)70086-9

2. Wormald PJ, Wee DT, van Hasselt CA. Endoscopic ligation of the sphenopalatine artery for refractory posterior epistaxis. Am J Rhinol. 2000;14(4):261-4. https:// doi.org/10.2500/105065800779954455

3. Vermeeren L, Derks W, Fokkens W, Menger DJ. Complications of balloon packing in epistaxis. Eur Arch Otorhinolaryngol. 2015;272(10):307781. https://doi.org/10.1007/s00405-0153529-5

4. Sigdel B, Nepali R, Neeraj KC, Dubey T, Neupane B, Sigdel D. Etiological Profile and Management of Epistaxis in Tertiary Care Hospital. Journal of Gandaki Medical College-Nepal. 2019;12(1):136. $\quad$ https://doi.org/10.3126/jgmen. v12i1.22603

5. Rotenberg B, Tam S. Respiratory complications from nasal packing: systematic review. $J$ Otolaryngol Head Neck Surg. 2010;39(5):606-14. Available from: https://pubmed.ncbi. nlm.nih.gov/20828527/[Accessed 25th
October 2020]

6. Nair KK. Transantral ligation of the internal maxillary artery. The Laryngoscope 1982;92:1060-3. https:// doi.org/10.1288/00005537-19820900000017

7. Strong EB, Bell DA, Johnson LP, Jacobs JM. Intractable epistaxis: transantral ligation vs. embolization: efficacy review and cost analysis. Otolaryngol Head Neck Surg. 1995;113(6):674-8. https:// doi.org/10.1016/S0194-5998(95)70004$\underline{8}$

8. Snyderman $\mathrm{CH}$, Goldman SA, Carrau RL, Ferguson BJ, Grandis JR. Endoscopic sphenopalatine artery ligation is an effective methodof treatment for posterior epistaxis. Am J Rhinol. 1999;13(2):137-40. https://doi. org/10.2500/105065899782106805

9. Hunter K and Gibson R. Arterial ligation for severe epistaxis. J Laryngol Otol.1969; 83(11):1099-1103. https:// doi.org/10.1017/S0022215100071383

10. Swords C, Patel A, Smith ME, Williams RJ, Kuhn I, Hopkins C. Surgical and interventional radiological management of adult epistaxis: systematic review. The J Laryngol Otol. 2017;131(12):1108$30 . \quad$ https://doi.org/10.1017/ $\underline{\mathrm{S} 0022215117002079}$

11. Tajudeen BA, Kennedy DW. Thirty years of endoscopic sinus surgery: What have we learned?. World J Otorhinolaryngol Head Neck Surg. 2017;3(2):115$21 . \quad$ https://doi.org/10.1016/j. wjorl.2016.12.001

12. Ellinas A, Jervis P, Kenyon G, Flood LM. Endoscopic sphenopalatine artery ligation for acute idiopathic epistaxis. Do anatomical variation and a limited evidence base raise questions regarding its place in management?. J Laryngol Otol. 2017;131(4):290-7. https://doi. org/10.1017/S0022215117000214

13. Sireci F, Speciale R, Sorrentino R, Turri-Zanoni M, Nicolotti M, Canevari 
FR. Nasal packing in sphenopalatine artery bleeding: therapeutic or harmful?. Eur Arch Otorhinolaryngol. 2017;274(3):1501-5. $\quad$ https://doi. org/10.1007/s00405-016-4381-y

14. De Bonnecaze G, Gallois Y, Bonneville F, Vergez S, Chaput B, Serrano E. Transnasal endoscopic sphenopalatine artery ligation compared with embolization for intractable epistaxis: a long-term analysis. Am $J$ Rhinol Allergy. 2018;32(3):188-93. https://doi. org/10.1177/1945892418768584

15. Agreda B, Urpegui Á, Alfonso JI, Valles $H$. Ligation of the sphenopalatine artery in posterior epistaxis. Retrospective study of 50 patients. Acta Otorrinolaringol Esp. 2011;62(3):194-8. https://doi. org/10.1016/j.otorri.2010.11.005

16. Marin E, Watelet JB, Gevaert P, Van Zele T. Severe spontaneous epistaxis: retrospective study in a tertiary ENT centre. EEur Arch Otorhinolaryngol. 2019;276(6):1693-9. $\quad$ https://doi. org/10.1007/s00405-019-05392-x

17. Prades J. Endonasal microsurgery. Acta Otorinolaryngol Iber Am. 1970;21(2):184-92. Available from: https://pubmed.ncbi.nlm.nih. gov/5484577/ [Accessed 28th October 2020]

18. White PS. Endoscopic ligation of the sphenopalatine artery (ELSA): a preliminary description. $J$ Laryngol Otol. 1996;110(1):27-30. https://doi. org/10.1007/s12070-010-0054-0

19. Paul J, Kanotra SP, Kanotra S. Endoscopic management of posterior epistaxis. Indian J Otolaryngol Head Neck Surg. 2011;63(2):141-4. https:// doi.org/10.1007/s12070-010-0054-0

20. Hervochon R, Khoueir N, Le Clerc N, Clément J, Kania R, Herman $\mathrm{P}$ et al. Unilateral vs bilateral sphenopalatine artery ligation in adult unilateral epistaxis: A comparative retrospective study of 83 cases. Clin Otolaryngol.
2018;43(6):1591-4.

https://doi. org/10.1111/coa.13183

21. Hey SY, Koo Ng NK, McGarry GW. Endoscopic sphenopalatine artery ligation: general applicability in a teaching unit. Ear Nose Throat J. 2019;98(2):85-8. https://doi. org/10.1177/0145561319828675

22. Kumar S, Shetty A, Rockey J, Nilssen E. Contemporary surgical treatment of epistaxis. What is the evidence for sphenopalatine artery ligation?. Clin Otolaryngol Allied Sci. 200328(4):3603. $\quad$ https://doi.org/10.1046/j.13652273.2003.00724.x

23. Huyett P, Jankowitz BT, Wang EW, et al. Endovascular Embolization in the Treatment of Epistaxis. OtolaryngologyHead and Neck Surgery. 2019; 160: 822-8. https://doi.org/10.1046/j.13652273.2003.00724.x

24. Jonas N, Viani L, Walsh $\mathrm{M}$. Sphenopalatine artery ligation under local anesthesia: A report of two cases and review of the literature. Local Reg Anesth. 2010;3:1-4. https://doi. org/10.2147/LRA.S6770 